\title{
Association of the LIPG 584C > T polymorphism and serum lipid levels in the Guangxi Bai Ku Yao and Han populations
}

Wan-Ying Liu', Rui-Xing Yin ${ }^{1 *}$, Lin Zhang ${ }^{1}$, Xiao-Li Cao ${ }^{1}$, Lin Miao ${ }^{1}$, Dong-Feng Wu' ${ }^{1}$, Lynn Htet Htet Aung ${ }^{1}$, Xi-Jiang Hu', Wei-Xiong Lin², De-Zhai Yang ${ }^{2}$

\begin{abstract}
Background: Endothelial lipase (EL) is a major determinant of high-density lipoprotein-cholesterol (HDL-C) metabolism, but the association of endothelial lipase gene (LIPG) polymorphism and serum HDL-C levels is scarce and conflicting in diverse populations. Bai Ku Yao is an isolated subgroup of the Yao minority in China. This study was designed to detect the association of LIPG 584C > T (rs2000813) polymorphism and several environmental factors with serum lipid levels in the Guangxi Bai Ku Yao and Han populations.
\end{abstract}

Methods: A total of 645 subjects of Bai Ku Yao and 638 participants of Han Chinese were randomly selected from our previous stratified randomized cluster samples. Genotyping of the LIPG 584C > T was performed by polymerase chain reaction and restriction fragment length polymorphism combined with gel electrophoresis, and then confirmed by direct sequencing.

Results: The levels of serum total cholesterol (TC), HDL-C, low-density lipoprotein cholesterol (LDL-C) and apolipoprotein (Apo) Al and ApoB were lower in Bai Ku Yao than in Han $(P<0.05-0.001)$. The frequency of $C$ and T alleles was $73.5 \%$ and $26.5 \%$ in Bai Ku Yao, and $67.9 \%$ and $32.1 \%$ in Han $(P<0.01)$; respectively. The frequency of CC, CT and TT genotypes was 50.4\%, 46.2\% and 3.4\% in Bai Ku Yao, and 41.4\%, 53.1\% and 5.5\% in Han $(P<0.01)$; respectively. Serum HDL-C levels in both ethnic groups were different among the three genotypes $(P<0.05$ for each). Serum TC levels in both ethnic groups were also different between the CC and CT/TT genotypes $(P<0.05$ for each). The T allele carriers had higher serum HDL-C and TC levels than the T allele noncarriers. Multivariate logistic regression analysis showed that the levels of $\mathrm{HDL}-\mathrm{C}$ and $\mathrm{ApoB}$ were correlated with genotypes in Bai $\mathrm{Ku}$ Yao $(P<0.05$ for each), whereas the levels of TC and HDL-C were associated with genotypes in Han Chinese $(P<$ 0.05 and $P<0.01$ ). Serum lipid parameters were also correlated with several environmental factors in the both ethnic groups.

Conclusions: The frequency of LIPG 584T allele is lower in Bai Ku Yao than in Han Chinese. The LIPG 584T allele is associated with increased serum HDL-C, TC and ApoB levels. The differences in serum HDL-C, TC and ApoB levels between the two ethnic groups might partly result from different genotypic and allelic frequencies of LIPG 584C > $T$ or different $L I P G$-enviromental interactions.

\footnotetext{
* Correspondence: yinruixing@yahoo.com.cn

'Department of Cardiology, Institute of Cardiovascular Diseases, the First Affiliated Hospital, Guangxi Medical University, 22 Shuangyong Road,

Nanning 530021, Guangxi, People's Republic of China

Full list of author information is available at the end of the article
} 


\section{Introduction}

Many epidemiological and clinical studies have shown that dyslipidemia, including high levels of plasma or serum total cholesterol (TC) [1,2], triglyceride (TG) $[3,4]$, low-density lipoprotein cholesterol (LDL-C) $[5,6]$ and apolipoprotein $\mathrm{B}$ (ApoB) $[7,8]$, and low levels of high-density lipoprotein cholesterol (HDL-C) and ApoAI $[9,10]$, is strongly associated with an increased risk of coronary artery disease (CAD). It is generally accepted that dyslipidemia is a polygenic disease with pathogenic contributions from both genetic and environmental risk factors such as demographics [11], diet [12], alcohol consumption [13], cigarette smoking $[13,14]$, obesity [15], physical activity [16], hypertension [17]. Data from family and twin studies suggest that genetic variation accounts for $40 \%-60 \%$ of the individual variation in serum lipid concentrations [18-20].

Endothelial lipase (protein: EL; gene: LIPG) is a member of the triglyceride lipase family of proteins that includes lipoprotein lipase and hepatic lipase, and it exhibits a conserved catalytic triad, heparin-binding properties, lipid-binding domains, and cysteine residues [21]. EL is produced by endothelial cells as well as by other cell types such as macrophages and hepatocytes. LIPG spans 10 exons and 9 introns and encodes a polypeptide of 500 amino acids. The EL cDNA shares $45 \%$ homology with lipoprotein lipase and 40\% homology with hepatic lipase and contains three conserved catalytic residues $[21,22]$. EL has phospholipase activity, but relatively little triglyceride lipase activity (phospholipase to triglyceride lipase ratio, 1.6) [23-25]. It has been demonstrated that overexpression of EL in the liver by adenovirus-mediated gene transfer results in a significant decrease in HDL-C and ApoAI [21]. Among the genetic variants of the LIPG, a common single nucleotide polymorphism (SNP), 584C > T, in exon 3 deserved greater scrutiny, as it was responsible for a significant amino acid change $(584 \mathrm{C}>\mathrm{T}$, Thr111Ile) that could potentially be associated with altered EL activity. Studies in mouse models showed that a decrease in EL expression and activity, by gene deletion of LIPG in knockout mice $[26,27]$ and by antibody inhibition [28], resulted in significant increases in plasma HDL-C in mice. Furthermore, overexpression of LIPG in transgenic mice resulted in decreased plasma HDL [21]. The LIPG 584C $>\mathrm{T}$ (rs2000813) polymorphism in humans has been found to be associated with modifications of serum HDL-C levels in some studies [27,29-32] but not in others [33-37].

Han is the largest ethnic group and Yao is the eleventh largest minority among the 55 minority groups according to the population size. Bai Ku Yao (Whitetrouser Yao), an isolated ethnic subgroup of the Yao minority, is named so because all the men wear white knee-length knickerbockers. The population size is about 30000 . Because of isolation from the other ethnic groups, the special customs and cultures including their clothing, intra-ethnic marriages, dietary habits, and lifestyle are still completely preserved to the present day. In several previous epidemiologic study, we found that the serum lipid levels and the prevalence of hyperlipidemia were lower in Bai Ku Yao than in Han Chinese from the same area $[38,39]$. This ethnic difference in serum lipid profiles is still not well known. We hypothesized that some gene polymorphisms may be different between the two ethnic groups. Therefore, in the present study, we examined the associations of LIPG 584C $>\mathrm{T}$ polymorphism and several environmental factors with serum lipid levels in the Guangxi Bai $\mathrm{Ku} \mathrm{Yao}$ and Han populations.

\section{Materials and methods Study population}

A total of 645 subjects of Bai Ku Yao who reside in Lihu and Baxu villages in Nandan County, Guangxi Zhuang Autonomous Region, People's Republic of China were randomly selected from our previous stratified randomized cluster samples [38,39]. The ages of the subjects ranged from 15 to 85 years, with an average age of $40.25 \pm 15.28$ years. There were 337 males $(52.25 \%)$ and 308 females $(47.75 \%)$. All subjects were rural agricultural workers. The subjects accounted for $2.15 \%$ of total Bai $\mathrm{Ku}$ Yao population. During the same period, a total of 638 people of Han Chinese who reside in the same villages were also randomly selected from our previous stratified randomized cluster samples $[38,39]$. The mean age of the subjects was $40.53 \pm 15.54$ years (range 15 to $82)$. There were 343 men (53.76\%) and 295 women (46.24\%). All of them were also rural agricultural workers. All study subjects had no evidence of any chronic illness, including hepatic, renal, or thyroid. The participants with a history of heart attack or myocardial infarction, stroke, congestive heart failure, diabetes or fasting blood glucose $\geq 7.0 \mathrm{mmol} / \mathrm{L}$ determined by glucose meter have been excluded. The participants were not taking medications known to affect serum lipid levels (lipid-lowering drugs such as statins or fibrates, betablockers, diuretics, or hormones). The present study was approved by the Ethics Committee of the First Affiliated Hospital, Guangxi Medical University. Informed consent was obtained from all subjects after they received a full explanation of the study.

\section{Epidemiological survey}

The survey was carried out using internationally standardized methods, following a common protocol [40]. 
Information on demographics, socioeconomic status, and lifestyle factors was collected with standardized questionnaires. The alcohol information included questions about the number of liangs (about $50 \mathrm{~g}$ ) of rice wine, corn wine, rum, beer, or liquor consumed during the preceding 12 months. Alcohol consumption was categorized into groups of grams of alcohol per day: $<25$ and $\geq 25$. Smoking status was categorized into groups of cigarettes per day: $<20$ and $\geq 20$. At the physical examination, several anthropometric parameters, such as height, weight, and waist circumference were measured. Sitting blood pressure was measured three times with the use of a mercury sphygmomanometer after the subjects had a 5-minute rest, and the average of the three measurements was used for the blood pressure levels. Systolic blood pressure was determined by the first Korotkoff sound, and diastolic blood pressure by the fifth Korotkoff sound. Body weight, to the nearest 50 grams, was measured using a portable balance scale. Subjects were weighed without shoes and in a minimum of clothing. Height was measured, to the nearest $0.5 \mathrm{~cm}$, using a portable steel measuring device. From these two measurements body mass index $\left(\mathrm{BMI}, \mathrm{kg} / \mathrm{m}^{2}\right)$ was calculated.

\section{Laboratory methods}

A venous blood sample of $8 \mathrm{ml}$ was obtained from all subjects between 8 and 11 AM, after at least 12 hours of fasting, from a forearm vein after venous occlusion for few seconds in a sitting position. A part of the sample $(3 \mathrm{ml})$ was collected into glass tube and used to determine serum lipid levels. Another part of the sample (5 ml) was transferred to tubes with anticoagulate solution $(4.80 \mathrm{~g} / \mathrm{L}$ citric acid, $14.70 \mathrm{~g} / \mathrm{L}$ glucose, and 13.20 $\mathrm{g} / \mathrm{L}$ tri-sodium citrate) and used to extract DNA. Immediately following clotting serum was separated by centrifugation for 15 minutes at $3000 \mathrm{rpm}$. The levels of TC, TG, HDL-C, and LDL-C in samples were determined by enzymatic methods with commercially available kits, Tcho-1, TG-LH (RANDOX Laboratories Ltd., Ardmore, Diamond Road, Crumlin Co. Antrim, United Kingdom, BT29 4QY), Cholestest N HDL, and Cholestest LDL (Daiichi Pure Chemicals Co., Ltd., Tokyo, Japan), respectively. Serum ApoAI and ApoB levels were detected by the immunoturbidimetric immunoassay using a commercial kit (RANDOX Laboratories Ltd.). All determinations were performed with an autoanalyzer (Type 7170A; Hitachi Ltd., Tokyo, Japan) in the Clinical Science Experiment Center of the First Affiliated Hospital, Guangxi Medical University [38,39].

\section{Genetic analysis}

Genomic DNA was isolated from peripheral blood leukocytes using the phenol-chloroform method $[41,42]$. The extracted DNA was stored at $4{ }^{\circ} \mathrm{C}$ until analysis. Genotyping of the LIPG $584 \mathrm{C}>\mathrm{T}$ was performed by polymerase chain reaction and restriction fragment length polymorphism (PCR-RFLP) [37]. LIPG genotypes were determined using mutagenic oligonucleotide primers with sequences 5'-CATGAGCTGAGATTGTTGTCAGTGC-3' and 5'CAGTCAACCACAACTACATTGGCGTCTTTCTCTCAT-3' (Sangon, Shanghai, People's Republic of China). Each amplification reaction was performed in a total volume of $25 \mathrm{~mL}$, containing $10 \times$ PCR buffer $(1.8 \mathrm{mM}$ $\left.\mathrm{MgCl}_{2}\right) 2.5 \mu \mathrm{L}, 1 \mathrm{U} \mathrm{Taq}$ polymerase, $2.5 \mathrm{mmol} / \mathrm{L}$ of each dNTP (Tiangen, Beijing, People's Republic of China) 2.0 $\mu \mathrm{L}, 20 \mathrm{pmol} / \mathrm{L}$ of each primer and $50 \mathrm{ng}$ of genomic DNA, processing started with $94^{\circ} \mathrm{C}$ for $5 \mathrm{~min}$ and 30 cycles at $94^{\circ} \mathrm{C}$ for $30 \mathrm{~s}, 58.8^{\circ} \mathrm{C}$ for $30 \mathrm{~s}$ and $72^{\circ} \mathrm{C}$ for $30 \mathrm{~s}$. This was followed by a final extension at $72^{\circ} \mathrm{C}$ for $4 \mathrm{~min}$. Then $10 \mathrm{U}$ of NdeI enzyme was added directly to the PCR products $(10 \mu \mathrm{L})$ and digested at $37^{\circ} \mathrm{C}$ overnight. After restriction enzyme digestion of the amplified DNA, genotypes were identified by electrophoresis on 3\% agarose gels and visualized with ethidium-bromide staining ultraviolet illumination. Genotypes were scored by an experienced reader blinded to epidemiological and serum lipid data. Six samples (CC, CT and TT genotypes in two, respectively) detected by the PCR-RFLP were also confirmed by direct sequencing. The PCR product was purified by low melting point gel electrophoresis and phenol extraction, and then the DNA sequence was analyzed in Shanghai Sangon Biological Engineering Technology \& Services Co., Ltd., People's Republic of China.

\section{Diagnostic criteria}

The normal values of serum TC, TG, HDL-C, LDL-C, ApoAI and ApoB levels, and the ratio of ApoAI to ApoB in our Clinical Science Experiment Center were 3.10-5.17, 0.56-1.70, 0.91-1.81, 2.70-3.20 mmol/L, $1.00-1.78,0.63-1.14 \mathrm{~g} / \mathrm{L}$, and 1.00-2.50; respectively. The individuals with TC $>5.17 \mathrm{mmol} / \mathrm{L}$ and/or TG > $1.70 \mathrm{mmol} / \mathrm{L}$ were defined as hyperlipidemic $[38,39]$. Hypertension was diagnosed according to the criteria of 1999 World Health Organization-International Society of Hypertension Guidelines for the management of hypertension $[43,44]$. The diagnostic criteria of overweight and obesity were according to the Cooperative Meta-analysis Group of China Obesity Task Force. Normal weight, overweight and obesity were defined as a $\mathrm{BMI}<24,24-28$, and $>28 \mathrm{~kg} / \mathrm{m}^{2}$; respectively [45].

\section{Statistical analyses}

Epidemiological data were recorded on a predesigned form and managed with Excel software. All statistical analyses were done with the statistical software package SPSS 13.0 (SPSS Inc., Chicago, Illinois). 
Quantitative variables were expressed as mean \pm standard deviation (serum TG levels were presented as medians and interquartile ranges). Qualitative variables were presented as percentages. Allele frequency was determined via direct counting, and the standard goodness-of-fit test was used to test the Hardy-Weinberg equilibrium. Differences in genotype distribution between the ethnic groups were obtained using the chi-square test. The difference in general characteristics between Bai Ku Yao and Han Chinese was tested by the Student's unpaired $t$-test (TG by the Wilcoxon-Mann-Whitney test). The association of genotypes with serum lipid parameters was tested by analysis of covariance (TG by the Kruskal-Wallis test or the Wilcoxon-Mann-Whitney test). Sex, age, BMI, blood pressure, alcohol intake, cigarette smoking were adjusted for the statistical analysis. In order to evaluate the association of serum lipid levels with genotypes and several environment factors, multivariate logistic regression analysis was also performed in the combined population of Bai Ku Yao and Han, Bai $\mathrm{Ku}$ Yao, and Han; respectively. A $P$ value of less than 0.05 was considered statistically significant.

\section{Results}

\section{General characteristics and serum lipid levels}

Table 1 gives the general characteristics and serum lipid levels between the Bai $\mathrm{Ku}$ Yao and Han populations. The levels of body height, weight, BMI, systolic blood pressure, diastolic blood pressure, pulse pressure, serum TC, HDL-C, LDL-C, ApoAI, and ApoB were lower in Bai Ku Yao than in Han $(P<0.05-0.001)$, whereas the percentage of subjects who consumed alcohol was higher in Bai Ku Yao than in Han $(P<0.05)$. There was no significant difference in serum TG levels, age structure, the percentage of subjects who smoked cigarettes, and the ratio of ApoAI to ApoB, or the ratio of male to female between the two ethnic groups $(P>0.05)$.

\section{Results of electrophoresis and genotyping}

After the genomic DNA of the samples was amplified by PCR and imaged by 3\% agarose gel electrophoresis, the purpose gene of $254 \mathrm{bp}$ nucleotide sequences could be found in all samples (Figure 1). The genotypes identified were named according to the presence or absence of the enzyme restriction sites, when a $\mathrm{C}$ to $\mathrm{T}$ transversion at nucleotide position 584 of the LIPG. For the C allele,

Table 1 The general characteristics and serum lipid levels between the Bai Ku Yao and Han populations

\begin{tabular}{|c|c|c|c|c|}
\hline Parameter & Bai Ku Yao & Han Chinese & $t\left(\chi^{2}\right)$ & $P$ \\
\hline Number & 645 & 638 & - & - \\
\hline Male/female & $337 / 308$ & $343 / 295$ & 0.295 & 0.587 \\
\hline Age (years) & $40.25 \pm 15.28$ & $40.53 \pm 15.54$ & -0.327 & 0.743 \\
\hline Height (cm) & $153.04 \pm 7.17$ & $156.14 \pm 7.97$ & -7.322 & 0.000 \\
\hline Weight (kg) & $51.53 \pm 7.15$ & $54.83 \pm 9.38$ & -7.079 & 0.000 \\
\hline Body mass index $\left(\mathrm{kg} / \mathrm{m}^{2}\right)$ & $21.97 \pm 2.37$ & $22.45 \pm 3.23$ & -3.080 & 0.002 \\
\hline Systolic blood pressure (mmHg) & $117.03 \pm 16.07$ & $120.89 \pm 16.45$ & -4.251 & 0.000 \\
\hline Diastolic blood pressure (mmHg) & $74.92 \pm 9.11$ & $76.46 \pm 10.77$ & -2.767 & 0.006 \\
\hline Pulse pressure $(\mathrm{mmHg})$ & $42.11 \pm 11.96$ & $44.47 \pm 11.26$ & -3.632 & 0.000 \\
\hline \multicolumn{5}{|l|}{ Cigarette smoking [n (\%)] } \\
\hline Nonsmoker & $451(69.9)$ & $440(69.0)$ & & \\
\hline$<20$ cigarettes/day & $88(13.6)$ & $80(12.5)$ & & \\
\hline$\geq 20$ cigarettes/day & $106(16.5)$ & $118(18.5)$ & 1.121 & 0.571 \\
\hline \multicolumn{5}{|l|}{ Alcohol consumption [n (\%)] } \\
\hline Nondrinker & $363(56.3)$ & $400(62.7)$ & & \\
\hline$<25$ g/day & $183(28.4)$ & $146(22.9)$ & & \\
\hline$\geq 25$ g/day & $99(15.3)$ & $92(14.4)$ & 6.174 & 0.046 \\
\hline Total cholesterol (mmol/L) & $4.28 \pm 0.93$ & $4.68 \pm 1.05$ & -7.315 & 0.000 \\
\hline Triglyceride $(\mathrm{mmol} / \mathrm{L})^{a}$ & $1.02(0.71)$ & $0.98(0.73)$ & -0.450 & 0.653 \\
\hline $\mathrm{HDL}-\mathrm{C}(\mathrm{mmol} / \mathrm{L})$ & $1.62 \pm 0.42$ & $1.87 \pm 0.49$ & -9.779 & 0.000 \\
\hline LDL-C (mmol/L) & $2.51 \pm 0.77$ & $2.60 \pm 0.77$ & -2.148 & 0.032 \\
\hline Apolipoprotein (Apo) Al (g/L) & $1.28 \pm 0.33$ & $1.41 \pm 0.27$ & -7.862 & 0.000 \\
\hline ApoB $(g / L)$ & $0.83 \pm 0.23$ & $0.88 \pm 0.22$ & -4.115 & 0.000 \\
\hline ApoAl/ApoB & $1.67 \pm 0.77$ & $1.70 \pm 0.53$ & -0.575 & 0.565 \\
\hline
\end{tabular}

HDL-C, high-density lipoprotein cholesterol; LDL-C, low-density lipoprotein cholesterol. ${ }^{\text {a }}$ The value of TG was presented as median (interquartile range). The difference between the two ethnic groups was determined by the Wilcoxon-Mann-Whitney test. 


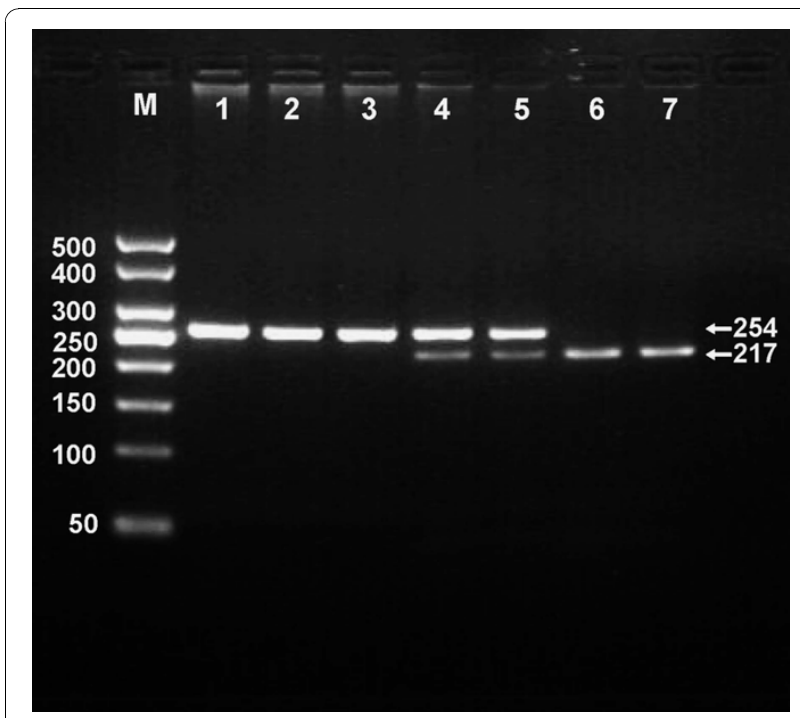

Figure 1 Genotyping of the LIPG 584C > T polymorphism. Lane M, 50 bp Marker Ladder; lane 1, the PCR product of the sample (254 bp); lanes 2 and 3, CC genotype (254 bp); lanes 4 and 5, CT genotype (254-, 217- and 37-bp); and lanes 6 and 7, $\Pi$ genotype (217- and 37-bp). The $37 \mathrm{bp}$ fragment was invisible in the gel owing to its fast migration speed.

there was no site for NdeI; for the T allele, NdeI digestion produced 217 - and 37 -bp products. Thus, the CC genotype is homozygote for the absence of the site (band at $254 \mathrm{bp}$ ), CT genotype is heterozygote for the absence and presence of the site (bands at 254-, 217and 37-bp), and TT genotype is homozygote for the presence the site (bands at 217- and 37-bp; Figure 1). The 37 bp fragment was invisible in the gel owing to its fast migration speed. The genotype distribution was consistent with the Hardy-Weinberg equilibrium.

\section{Genotypic and allelic frequencies}

The frequencies of the LIPG 584C > T alleles and genotypes are shown in Table 2. The frequencies of $\mathrm{C}$ and $\mathrm{T}$ alleles were $73.5 \%$ and $26.5 \%$ in Bai $\mathrm{Ku}$ Yao, and $67.9 \%$ and $32.1 \%$ in Han $(P<0.01)$; respectively. The frequencies of CC, CT and TT genotypes were 50.4\%, 46.2\% and $3.4 \%$ in Bai $\mathrm{Ku} \mathrm{Yao,} \mathrm{and} 41.4 \%, 53.1 \%$ and $5.5 \%$ in Han $(P<0.01)$; respectively.

Table 2 Genotypic and allelic frequencies of the LIPG 584C > T polymorphism between the Bai Ku Yao and Han population [n (\%)]

\begin{tabular}{lcccc|cc}
\hline \multirow{2}{*}{ Group } & \multirow{n}{*}{$\mathbf{n}$} & \multicolumn{3}{c|}{ Genotype } & \multicolumn{2}{c}{ Allele } \\
\cline { 3 - 7 } & & CC & CT & TT & C & T \\
\hline Bai Ku Yao & 645 & $325(50.4)$ & $298(46.2)$ & $22(3.4)$ & $948(73.5)$ & $342(26.5)$ \\
Han Chinese & 638 & $264(41.4)$ & $339(53.1)$ & $35(5.5)$ & $867(67.9)$ & $409(32.1)$ \\
$\chi^{2}$ & - & & 11.883 & & \multicolumn{2}{c}{9.516} \\
$P$ & - & & 0.003 & & \multicolumn{2}{c}{0.002} \\
\hline
\end{tabular}

\section{Results of sequencing}

The results shown as $\mathrm{CC}, \mathrm{CT}$ and $\mathrm{TT}$ genotypes by PCR-RFLP, CC, CT and TT genotypes were also confirmed by sequencing (Figure 2).

\section{Genotypes and serum lipid levels}

As shown in Table 3, the levels of HDL-C in both ethnic groups were different among the three genotypes $(P<0.05$ for each). The levels of TC, HDL-C and ApoAI in Bai $\mathrm{Ku}$ Yao and the levels of TC and TG in Han were different between $\mathrm{CC}$ and $\mathrm{CT} / \mathrm{TT}$ genotypes $(P<0.05$ for all $)$. The $\mathrm{T}$ allele carriers had higher serum lipid levels than the $\mathrm{T}$ allele noncarriers. There was no significant difference in the levels of LDL-C, ApoB, and the ratio of ApoAI to ApoB among the three genotypes in the both ethnic groups $(P>0.05$ for all).

\section{Risk factors for the lipid parameters}

Multivariate logistic regression analysis showed that the levels of HDL-C and ApoB were correlated with genotypes in Bai $\mathrm{Ku}$ Yao $(P<0.05$ for each), whereas the levels of TC and HDL-C were associated with genotypes in Han Chinese $(P<0.05$ and $<0.01$; respectively). Serum lipid parameters were also correlated with sex, age, weight, BMI, alcohol consumption, cigarette smoking, and blood pressure in the both ethnic groups (Table 4).

\section{Discussion}

The present study shows that the serum levels of TC, HDL-C, LDL-C, ApoAI and ApoB were lower in Bai Ku Yao than in Han Chinese. There were no significant differences in serum TG levels and the ratio of ApoAI to ApoB between the two ethnic groups. These findings are consistent with those of our previous epidemiological studies [38,39]. It is well known that dyslipidemia is a complex trait caused by multiple environmental and genetic factors and their interactions. Bai $\mathrm{Ku}$ Yao is a special subgroup of the Yao minority in China. Strict intra-ethnic marriages have been performed in this population from time immemorial. Therefore, we believed that the hereditary characteristics and some lipid metabolism-related gene polymorphisms in this population may be different from those in Han Chinese.

The frequency of the rare allele $(584 \mathrm{~T})$ was found to be $10.3 \%$ in blacks, $31.2 \%$ in white controls, $32.6 \%$ in whites with high HDL-C [34], 26\% in the Lipoprotein and Coronary Atherosclerosis Study (LCAS) population (white individuals including 27 or $7 \%$ African Americans)[27], 26\% in Japanese [37], and $21.6 \%$ in healthy school-aged Japanese children [33]. In the present study, we showed that the frequency of the $\mathrm{T}$ allele and CT and TT genotypes was lower in Bai $\mathrm{Ku}$ Yao than in Han. The frequency of the $\mathrm{T}$ allele in Bai $\mathrm{Ku}$ Yao was 

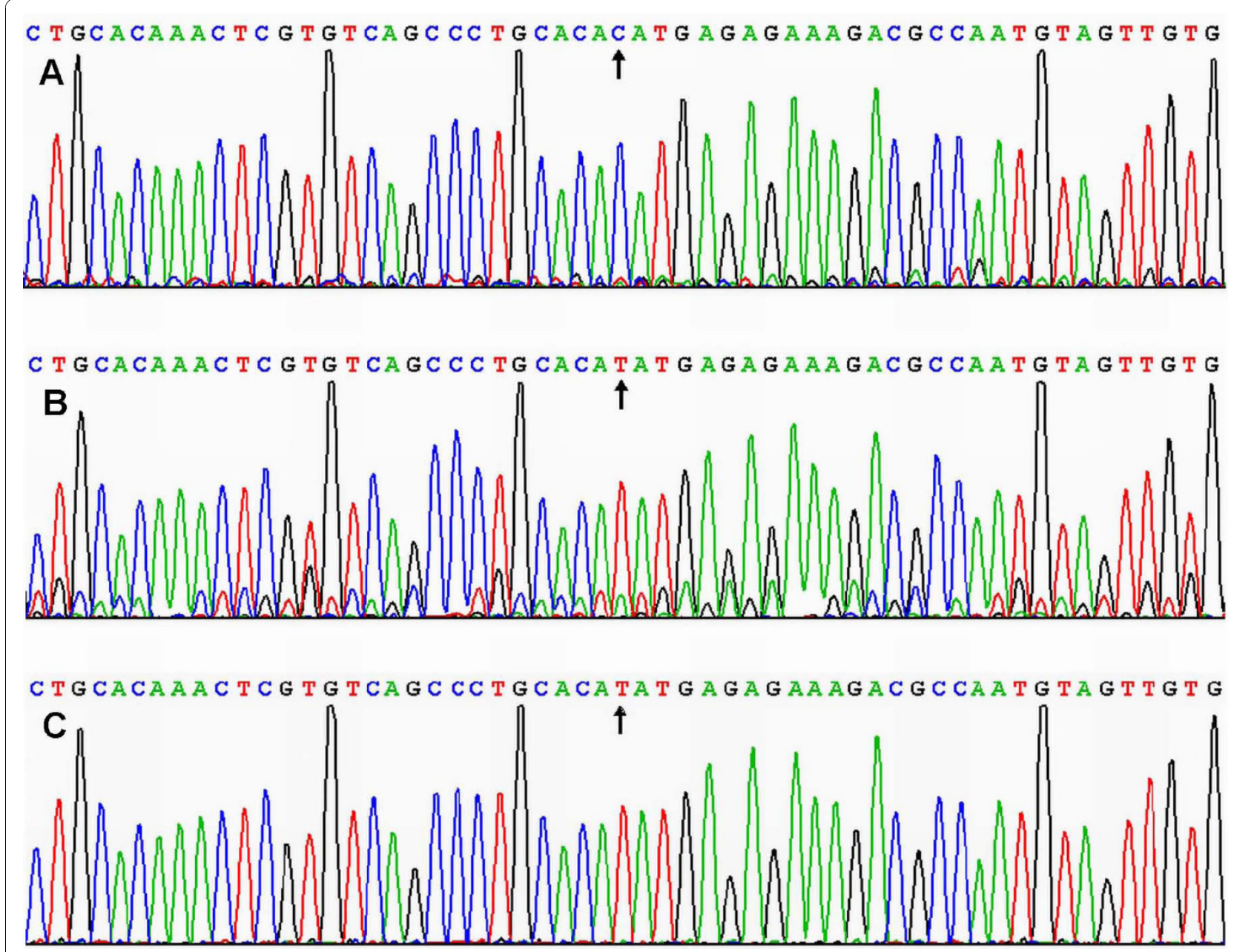

Figure $2 \mathrm{~A}$ part of the nucleotide sequence of the LIPG 584C > T polymorphism. (A) CC genotype; (B) CT genotype; (C) TT genotype

also lower than that of previous studies in white controls [34]. These results indicate that the LIPG 584C > $\mathrm{T}$ polymorphism may have significant difference in allele frequencies among diverse ethnics and between control subjects and those with high HDL-C levels. However, McCoy et al. [24] found that EL is completely inactive in vitro in the presence of serum, and deLemos et al. [34] found no significant difference in allele frequencies of six polymorphisms in the LIPG between individuals with normal and those with high HDL-C. Thus, the physiological role of EL in lipoprotein metabolism, if any, is still unknown.

The association between the LIPG $584 \mathrm{C}>\mathrm{T}$ polymorphism and plasma or serum lipid levels in humans has not been fully elucidated. In the present study, we found a significant association between the LIPG 584C $>\mathrm{T}$ polymorphism and serum HDL-C and TC levels. In the both Bai $\mathrm{Ku}$ Yao and Han populations, we can detect an increased prevalence of the $\mathrm{T}$ allele in subjects with higher serum HDL-C and TC levels. Previous association studies of this SNP with plasma HDL-C levels produced conflicting results. Several studies have reported significant association between the LIPG 584C $>\mathrm{T}$ polymorphism and HDL-C levels [27,29-32], whereas several reports failed to find a significant genetic effect on HDL-C concentrations [33-37]. Ma and colleagues [27] reported that the LIPG 584C > T polymorphism was associated with an increase in HDL$\mathrm{C}$ among 372 participants. The patients with the $\mathrm{T} \mathrm{T}$ genotype have a $14 \%$ higher mean HDL-C compared with those with the CC genotype. Yamakawa-Kobayashi et al. [33] failed to detect an association of the LIPG $584 \mathrm{C}>\mathrm{T}$ with HDL-C levels in 340 Japanese children. Paradis and co-workers [46] found an association of the LIPG 584C > T with increased levels of the $\mathrm{HDL}_{3}$ subfraction in 281 females. Halverstadt et al. [32] found an association of the LIPG 584C > T with NMR measurements of HDL size in 83 healthy elderly participants but not with overall HDL-C levels. Mank-Seymour et al. [29] showed a weak association of the LIPG 584C > T 
Table 3 Genotypic frequencies of the LIPG 584C > T and serum lipid levels between the Bai Ku Yao and Han populations

\begin{tabular}{|c|c|c|c|c|c|c|c|c|}
\hline Genotype & $\mathrm{n}$ & $\mathrm{TC}(\mathrm{mmol} / \mathrm{L})$ & $\mathrm{TG}(\mathrm{mmol} / \mathrm{L})^{\mathrm{a}}$ & $\mathrm{HDL}-\mathrm{C}(\mathrm{mmol} / \mathrm{L})$ & LDL-C (mmol/L) & ApoAl $(g / L)$ & ApoB (g/L) & ApoAl/ApoB \\
\hline \multicolumn{9}{|l|}{ Bai Ku Yao } \\
\hline CC & 325 & $4.20 \pm 0.87$ & $1.02(0.65)$ & $1.58 \pm 0.40$ & $2.48 \pm 0.71$ & $1.25 \pm 0.32$ & $0.82 \pm 0.22$ & $1.63 \pm 0.70$ \\
\hline $\mathrm{CT}$ & 298 & $4.34 \pm 1.00$ & $1.02(0.77)$ & $1.66 \pm 0.45$ & $2.52 \pm 0.83$ & $1.30 \pm 0.34$ & $0.83 \pm 0.23$ & $1.71 \pm 0.83$ \\
\hline$\pi$ & 22 & $4.51 \pm 0.71$ & $1.08(0.70)$ & $1.78 \pm 0.41$ & $2.58 \pm 0.63$ & $1.40 \pm 0.37$ & $0.88 \pm 0.25$ & $1.76 \pm 0.88$ \\
\hline$F$ & - & 2.114 & 1.160 & 3.318 & 0.171 & 2.536 & 0.381 & 0.776 \\
\hline$P$ & - & 0.122 & 0.314 & 0.037 & 0.843 & 0.080 & 0.683 & 0.461 \\
\hline $\mathrm{CC}$ & 325 & $4.20 \pm 0.87$ & $1.02(0.65)$ & $1.58 \pm 0.40$ & $2.48 \pm 0.71$ & $1.25 \pm 0.32$ & $0.82 \pm 0.22$ & $1.63 \pm 0.70$ \\
\hline $\mathrm{CT} / \mathrm{TT}$ & 320 & $4.35 \pm 0.98$ & $1.03(0.77)$ & $1.67 \pm 0.45$ & $2.53 \pm 0.82$ & $1.31 \pm 0.34$ & $0.83 \pm 0.23$ & $1.71 \pm 0.83$ \\
\hline$F$ & - & 3.894 & 1.774 & 5.414 & 0.310 & 3.902 & 0.119 & 1.522 \\
\hline P & - & 0.049 & 0.183 & 0.020 & 0.578 & 0.049 & 0.731 & 0.218 \\
\hline \multicolumn{9}{|c|}{ Han Chinese } \\
\hline CC & 264 & $4.57 \pm 0.88$ & $0.99(0.64)$ & $1.85 \pm 0.48$ & $2.54 \pm 0.71$ & $1.39 \pm 0.25$ & $0.87 \pm 0.21$ & $1.70 \pm 0.50$ \\
\hline CT & 339 & $4.77 \pm 1.18$ & $0.97(0.78)$ & $1.88 \pm 0.48$ & $2.65 \pm 0.82$ & $1.42 \pm 0.29$ & $0.89 \pm 0.22$ & $1.69 \pm 0.56$ \\
\hline$\pi$ & 35 & $4.75 \pm 0.91$ & $1.08(0.83)$ & $2.09 \pm 0.63$ & $2.49 \pm 0.67$ & $1.46 \pm 0.23$ & $0.91 \pm 0.22$ & $1.70 \pm 0.56$ \\
\hline$F$ & - & 2.959 & 2.781 & 3.904 & 1.951 & 1.549 & 1.215 & 0.012 \\
\hline$P$ & - & 0.053 & 0.063 & 0.021 & 0.143 & 0.213 & 0.297 & 0.988 \\
\hline CC & 264 & $4.57 \pm 0.88$ & $0.99(0.64)$ & $1.85 \pm 0.48$ & $2.54 \pm 0.71$ & $1.39 \pm 0.25$ & $0.87 \pm 0.21$ & $1.70 \pm 0.50$ \\
\hline $\mathrm{CT} / \mathrm{TT}$ & 374 & $4.76 \pm 1.15$ & $0.98(0.79)$ & $1.89 \pm 0.50$ & $2.63 \pm 0.80$ & $1.43 \pm 0.28$ & $0.89 \pm 0.22$ & $1.69 \pm 0.56$ \\
\hline$F$ & - & 5.894 & 4.462 & 1.880 & 2.399 & 2.559 & 2.090 & 0.743 \\
\hline P & - & 0.015 & 0.035 & 0.171 & 0.122 & 0.110 & 0.149 & 0.389 \\
\hline
\end{tabular}

TC, total cholesterol; TG, triglyceride; HDL-C, high-density lipoprotein cholesterol; LDL-C, low-density lipoprotein cholesterol; ApoAl, apolipoprotein Al; ApoB, apolipoprotein B; ApoAl/ApoB, the ratio of apolipoprotein Al to apolipoprotein B. ${ }^{\text {a }}$ The value of TG was presented as median (interquartile range). The difference among the genotypes was determined by the Kruskal-Wallis test or the Wilcoxon-Mann-Whitney test.

with increased HDL-C among 594 participants. Hutter et al. [30] found a weak association of the LIPG 584C > $\mathrm{T}$ with HDL-C levels in 541 Japanese Americans. Tang et al. [47] found a weak association of the LIPG 584C > $\mathrm{T}$ with increased HDL-C in 265 Chinese CAD cases and controls. The data by Edmondson et al. [36] from a combined sample of 3,845 participants, and functional studies of the variant definitively establish that the LIPG $584 \mathrm{C}>\mathrm{T}$ is not associated with HDL-C and in vitro studies show that it has normal lipolytic activity. The reason for these conflicting results is not yet known. The $584 \mathrm{C}>\mathrm{T}$ SNP results in an amino acid change (from a polar to nonpolar amino acid) that occurs in a relatively poorly conserved area of the EL sequence, far from important sites encoding for the catalytic activity of defining the tertiary structure of the enzyme [48]. The high prevalence of the minor allele also suggests that it may not have a large effect on plasma HDL-C levels in the general population [46]. In a previous study, however, Shimizu et al. [37] found no significant association between the LIPG 584C > T polymorphism and HDL-C levels, but multivariate regression analyses showed that the association of the LIPG 584T allele with acute myocardial infarction was statistically significant and independent of other risk factors when age, sex, hypertension, hypercholesterolemia, and diabetes mellitus were included in the analyses. Thus, the LIPG
$584 \mathrm{C}>\mathrm{T}$ polymorphism may be involved in the pathogenesis of acute myocardial infarction. In LCAS there was also a strong association of the LIPG 584C > T polymorphism with the ratios of HDL-C/LDL-C and ApoAI/ApoB, and the mean plasma ApoCIII concentration [27]. In the present study, we also showed that the levels of TC and ApoAI in Bai $\mathrm{Ku}$ Yao and the levels of TC and TG in Han were different between the CC and $\mathrm{CT} / \mathrm{TT}$ genotypes. The $\mathrm{T}$ allele carriers had higher serum lipid levels than the $\mathrm{T}$ allele noncarriers. In multivariate logistic regression analysis, the levels of HDL-C and $\mathrm{ApoB}$ were correlated with genotypes in Bai $\mathrm{Ku}$ Yao, whereas the levels of TC and HDL-C were associated with genotypes in Han Chinese. These results suggest that the LIPG $584 \mathrm{C}>\mathrm{T}$ polymorphism can also influence other serum lipid parameters except HDL-C in our populations.

As mentioned above, plasma lipid concentration is highly heritable but is also modifiable by environmental factors including demographics [11], diet [12], alcohol consumption [13], cigarette smoking [13,14], obesity [15], exercise [16], hypertension [17]. These factors could explain why the association between HDL-C concentration and the LIPG 584C > T polymorphism was not observed in some previous studies. For example, heavy smokers have, on average, 9\% lower HDL-C levels than matched nonsmokers [14]. Obesity is one of the 
Table 4 Correlative factors for the lipid paramerers between the Bai Ku Yao and Han populations

\begin{tabular}{|c|c|c|c|c|c|c|c|}
\hline Lipid & Relative factor & Regression coefficient & Standard error & $\chi^{2}$ & $P$ & Odds ratio & $95 \% \mathrm{Cl}$ \\
\hline \multicolumn{8}{|c|}{ Bai Ku Yao and Han } \\
\hline \multirow[t]{6}{*}{$\mathrm{TC}$} & Ethnic group & -0.559 & 0.149 & 14.085 & 0.000 & 0.572 & $0.427-0.766$ \\
\hline & Age & 0.020 & 0.005 & 14.060 & 0.000 & 1.020 & $1.010-1.031$ \\
\hline & Body mass index & 0.155 & 0.026 & 35.363 & 0.000 & 1.167 & $1.109-1.229$ \\
\hline & Systolic blood pressure & 0.020 & 0.008 & 7.225 & 0.007 & 1.021 & $1.006-1.036$ \\
\hline & Pulse pressure & -0.030 & 0.010 & 8.287 & 0.004 & 0.971 & $0.951-0.991$ \\
\hline & Alcohol consumption & 0.210 & 0.096 & 4.780 & 0.029 & 1.234 & $1.022-1.490$ \\
\hline \multirow[t]{4}{*}{ TG } & Sex & -0.665 & 0.182 & 13.347 & 0.000 & 0.514 & $0.360-0.735$ \\
\hline & Body mass index & 0.169 & 0.027 & 40.311 & 0.000 & 1.184 & $1.124-1.247$ \\
\hline & Alcohol consumption & 0.229 & 0.109 & 4.428 & 0.035 & 1.258 & $1.016-1.558$ \\
\hline & Genotype & 0.354 & 0.158 & 4.996 & 0.025 & 1.425 & $1.045-1.943$ \\
\hline \multirow[t]{4}{*}{$\mathrm{HDL}-\mathrm{C}$} & Ethnic group & 1.221 & 0.333 & 13.414 & 0.000 & 3.390 & $1.764-6.515$ \\
\hline & Sex & -1.209 & 0.346 & 12.244 & 0.000 & 0.298 & $0.152-0.588$ \\
\hline & Age & -0.037 & 0.012 & 9.899 & 0.002 & 0.964 & $0.942-0.986$ \\
\hline & Alcohol consumption & -0.612 & 0.270 & 5.157 & 0.023 & 0.542 & $0.320-0.920$ \\
\hline \multirow[t]{4}{*}{ LDL-C } & Age & 0.025 & 0.006 & 15.978 & 0.000 & 1.026 & $1.013-1.039$ \\
\hline & Body mass index & 0.174 & 0.029 & 35.023 & 0.000 & 1.190 & $1.123-1.261$ \\
\hline & Systolic blood pressure & 0.020 & 0.009 & 5.034 & 0.025 & 1.020 & $1.003-1.038$ \\
\hline & Alcohol consumption & -0.258 & 0.123 & 4.417 & 0.036 & 0.772 & $0.607-0.983$ \\
\hline \multirow[t]{5}{*}{ ApoAl } & Ethnic group & 1.450 & 0.142 & 104.456 & 0.000 & 4.264 & $3.229-5.631$ \\
\hline & Sex & -0.720 & 0.154 & 21.860 & 0.000 & 0.487 & $0.360-0.658$ \\
\hline & Age & -0.033 & 0.005 & 45.064 & 0.000 & 0.968 & $0.958-0.977$ \\
\hline & Diastolic blood pressure & -0.022 & 0.008 & 8.463 & 0.004 & 0.978 & $0.964-0.993$ \\
\hline & Alcohol consumption & -0.773 & 0.118 & 42.820 & 0.000 & 0.462 & $0.366-0.582$ \\
\hline \multirow[t]{3}{*}{ ApoB } & Age & 0.026 & 0.007 & 15.328 & 0.000 & 1.026 & $1.013-1.039$ \\
\hline & Body mass index & 0.175 & 0.030 & 33.906 & 0.000 & 1.191 & $1.123-1.263$ \\
\hline & Pulse pressure & -0.025 & 0.012 & 4.047 & 0.044 & 0.976 & $0.952-0.999$ \\
\hline \multirow[t]{3}{*}{ ApoAl/ApoB } & Ethnic group & 0.704 & 0.181 & 15.128 & 0.000 & 2.022 & $1.418-2.884$ \\
\hline & Systolic blood pressure & 0.012 & 0.005 & 5.190 & 0.023 & 1.012 & $1.002-1.022$ \\
\hline & Alcohol consumption & 0.401 & 0.110 & 13.280 & 0.000 & 1.494 & $1.204-1.854$ \\
\hline \multicolumn{8}{|l|}{ Bai Ku Yao } \\
\hline \multirow[t]{2}{*}{ TC } & Age & 0.029 & 0.008 & 14.523 & 0.000 & 1.030 & $1.014-1.045$ \\
\hline & Weight & 0.077 & 0.015 & 25.488 & 0.000 & 1.080 & $1.048-1.113$ \\
\hline \multirow[t]{2}{*}{$\mathrm{TG}$} & Sex & -0.833 & 0.229 & 13.299 & 0.000 & 0.435 & $0.278-0.680$ \\
\hline & Body mass index & 0.197 & 0.045 & 19.055 & 0.000 & 1.218 & $1.115-1.331$ \\
\hline \multirow[t]{3}{*}{$\mathrm{HDL}-\mathrm{C}$} & Sex & -1.044 & 0.394 & 7.031 & 0.008 & 0.352 & $0.163-0.762$ \\
\hline & Age & -0.033 & 0.014 & 5.814 & 0.016 & 0.968 & $0.943-0.994$ \\
\hline & Genotype & -0.273 & 0.196 & 4.627 & 0.040 & 0.652 & $0.950-0.990$ \\
\hline \multirow[t]{2}{*}{ LDL-C } & Age & 0.031 & 0.009 & 13.469 & 0.000 & 1.032 & $1.015-1.049$ \\
\hline & Weight & 0.065 & 0.017 & 15.009 & 0.000 & 1.067 & $1.032-1.102$ \\
\hline \multirow[t]{3}{*}{ ApoAl } & Sex & -0.546 & 0.208 & 6.898 & 0.009 & 0.579 & $0.386-0.871$ \\
\hline & Age & -0.029 & 0.006 & 23.998 & 0.000 & 0.971 & $0.960-0.983$ \\
\hline & Alcohol consumption & -0.800 & 0.151 & 27.987 & 0.000 & 0.449 & $0.334-0.604$ \\
\hline \multirow[t]{3}{*}{ ApoB } & Body mass index & 0.189 & 0.055 & 11.470 & 0.001 & 1.207 & $1.084-1.345$ \\
\hline & Diastolic blood pressure & 0.035 & 0.015 & 5.503 & 0.019 & 1.036 & $1.006-1.066$ \\
\hline & Genotype & 0.479 & 0.231 & 4.283 & 0.038 & 1.614 & $1.026-2.539$ \\
\hline ApoAl/ApoB & Alcohol consumption & 0.706 & 0.167 & 17.835 & 0.000 & 2.025 & $1.460-2.810$ \\
\hline \multicolumn{8}{|l|}{ Han Chinese } \\
\hline \multirow[t]{3}{*}{ TC } & Sex & 0.775 & 0.227 & 11.633 & 0.001 & 2.170 & $1.390-3.386$ \\
\hline & Age & 0.019 & 0.007 & 7.576 & 0.006 & 1.019 & $1.006-1.033$ \\
\hline & Weight & 0.057 & 0.011 & 25.915 & 0.000 & 1.059 & $1.036-1.082$ \\
\hline
\end{tabular}


Table 4 Correlative factors for the lipid paramerers between the Bai Ku Yao and Han populations (Continued)

\begin{tabular}{|c|c|c|c|c|c|c|c|}
\hline & Systolic blood pressure & 0.022 & 0.010 & 5.340 & 0.021 & 1.022 & $1.003-1.042$ \\
\hline & Pulse pressure & -0.035 & 0.014 & 6.611 & 0.010 & 0.966 & $0.940-0.992$ \\
\hline & Alcohol consumption & 0.286 & 0.140 & 4.150 & 0.042 & 1.331 & $1.011-1.751$ \\
\hline & Genotype & 0.327 & 0.148 & 4.886 & 0.027 & 1.387 & $1.038-1.854$ \\
\hline \multirow[t]{3}{*}{ TG } & Weight & 0.064 & 0.012 & 28.297 & 0.000 & 1.066 & $1.041-1.092$ \\
\hline & Systolic blood pressure & 0.015 & 0.007 & 4.789 & 0.029 & 1.015 & $1.002-1.029$ \\
\hline & Cigarette smoking & 0.318 & 0.132 & 5.855 & 0.016 & 1.375 & $1.062-1.779$ \\
\hline \multirow[t]{2}{*}{$\mathrm{HDL}-\mathrm{C}$} & Age & -0.062 & 0.023 & 7.056 & 0.008 & 0.940 & $0.898-0.984$ \\
\hline & Genotype & -0.432 & 0.189 & 7.274 & 0.008 & 0.654 & $0.430-0.890$ \\
\hline \multirow[t]{3}{*}{ LDL-C } & Age & 0.025 & 0.008 & 10.053 & 0.002 & 1.026 & $1.010-1.042$ \\
\hline & Body mass index & 0.115 & 0.051 & 5.128 & 0.024 & 1.122 & $1.016-1.240$ \\
\hline & Alcohol consumption & -0.449 & 0.177 & 6.438 & 0.011 & 0.638 & $0.451-0.903$ \\
\hline \multirow[t]{4}{*}{ ApoAl } & Sex & -1.074 & 0.244 & 19.359 & 0.000 & 0.342 & $0.212-0.551$ \\
\hline & Age & -0.043 & 0.008 & 27.185 & 0.000 & 0.958 & $0.942-0.973$ \\
\hline & Diastolic blood pressure & -0.033 & 0.012 & 7.657 & 0.006 & 0.967 & $0.945-0.990$ \\
\hline & Alcohol consumption & -0.558 & 0.186 & 8.973 & 0.003 & 0.572 & $0.397-0.825$ \\
\hline \multirow[t]{2}{*}{ ApoB } & Age & 0.030 & 0.008 & 13.584 & 0.000 & 1.030 & $1.014-1.047$ \\
\hline & Body mass index & 0.174 & 0.034 & 25.783 & 0.000 & 1.191 & $1.113-1.273$ \\
\hline ApoAl/ApoB & Systolic blood pressure & 0.022 & 0.008 & 7.514 & 0.006 & 1.022 & 1.006-1.038. \\
\hline
\end{tabular}

TC, total cholesterol; TG, triglyceride; HDL-C, high-density lipoprotein cholesterol; LDL-C, low-density lipoprotein cholesterol; ApoAl, apolipoprotein Al; ApoB, apolipoprotein B; ApoAl/ApoB, the ratio of apolipoprotein Al to apolipoprotein B.

most important factors in reducing HDL-C levels $[15,49]$. Evidences of association in different populations with different lifestyles and diet might suggest that the associations found are robust to a large number of genetic and environmental factors. In the present study, we found that many confounding factors affect serum lipid levels. Serum lipid parameters were correlated with age, sex, alcohol consumption, cigarette smoking, BMI, and blood pressure. These findings suggest that the environmental factors also play an important role in determing serum lipid levels in these populations. Differences in serum lipid levels between the two ethnic groups could be related to factors such as differences in the genetic background, dietary patterns and lifestyle factors and their interactions. Although Bai Ku Yao and Han reside in the same region, there was significant difference in their diet and lifestyle. Corn was the staple food and rice, soy, buckwheat, sweet potato, and pumpkin products were the subsidiary foods in Bai Ku Yao. Approximately $90 \%$ of the beverages were corn wine and rum. The alcohol content is about $15 \%(\mathrm{v} / \mathrm{v})$. They are also accustomed to drink Hempseed soup. In contrast, rice was the staple food and corn, broomcorn, potato, and taro products were the subsidiary foods in Han. About $90 \%$ of the beverage was rice wine. The content of alcohol is about $30 \%(\mathrm{v} / \mathrm{v})$. The staple and subsidiary foods are more favorable for serum lipid profiles in Bai Ku Yao than in Han. Corn contains abundant dietary fiber and plant protein. Dietary fiber can decrease serum TC levels [50]. Plant protein can promote the transportation and excretion of free cholesterol. Soy protein intake is effective in reducing TC by $9.3 \%$, LDL-C by $12.9 \%$, and TG by $10.5 \%$ and in increasing HDL-C by $2.4 \%$ [51]. Hypocholesterolemic activity of buckwheat protein product is far stronger than that of soy protein isolate [52]. Ludvik and his colleagues [53] found that ingestion of $4 \mathrm{~g} /$ day caiapo (the extract of white-skinned sweet potato) for 6 weeks reduces TC and LDL-C in type 2 diabetic patients previously treated by diet alone. Studies have demonstrated that pumpkin is a useful therapy for hypercholesterolemia through reducing oxidative stress and cholesterol levels [54]. A number of experimental and clinical studies have demonstrated that the beneficial effects of Hempseed or Hempseed oil on serum lipid profiles include: decreasing TC, TG and LDL-C levels $[54,55]$, inhibiting lipid peroxidation [55], reducing atherogenic index [56], and increasing HDL-C levels [55,56].

\section{Conclusion}

The results of the present study show that the LIPG $584 \mathrm{~T}$ allele frequency is lower in Bai Ku Yao than in Han Chinese. A significant association is found between the LIPG 584C > T polymorphism and serum HDL-C and TC levels in the both ethnic groups. An increased prevalence of the $584 \mathrm{~T}$ allele in subjects with higher serum HDL-C and TC levels is detected in the both populations. The levels of HDL-C and ApoB were correlated with genotypes in Bai $\mathrm{Ku}$ Yao, whereas the levels of TC and HDL-C were associated with genotypes in 
Han Chinese. The differences in serum HDL-C, TC and ApoB levels between the two ethnic groups might partly result from different $L I P G 584 \mathrm{C}>\mathrm{T}$ polymorphism or different $L I P G$-enviromental interactions.

\author{
Acknowledgements \\ This study was supported by the National Natural Science Foundation of \\ China (No: 30660061)
}

\begin{abstract}
Author details
${ }^{1}$ Department of Cardiology, Institute of Cardiovascular Diseases, the First Affiliated Hospital, Guangxi Medical University, 22 Shuangyong Road, Nanning 530021, Guangxi, People's Republic of China. ${ }^{2}$ Department of Molecular Biology, Medical Scientific Research Center, Guangxi Medical University, 22 Shuangyong Road, Nanning 530021, Guangxi, People's Republic of China.
\end{abstract}

\section{Authors' contributions}

WYL participated in the design, undertook genotyping, performed statistical analyses, and helped to draft the manuscript. RXY conceived the study, participated in the design, carried out the epidemiological survey, collected the samples, and drafted the manuscript. LZ, XLC, LM, DFW, LHHA and XJH collaborated to the genotyping. WXL and DZY carried out the epidemiological survey, collected the samples, and helped to carry out the genotyping. All authors read and approved the final manuscript.

\section{Competing interests}

The authors declare that they have no competing interests.

Received: 10 September 2010 Accepted: 6 October 2010 Published: 6 October 2010

\section{References}

1. Shekelle RB, Shryock AM, Paul O, Lepper M, Stamler J, Liu S, Raynor WJ Jr: Diet, serum cholesterol, and death from coronary heart disease. The Western Electric study. N Engl J Med 1981, 304:65-70.

2. Expert Panel on Detection Evaluation and Treatment of High Blood Cholesterol in Adults: Executive Summary of the third report of the National Cholesterol Education Program (NCEP) expert panel on detection, evaluation, and treatment of high blood cholesterol in adults (Adult Treatment Panel III). JAMA 2001, 285:2486-97.

3. Satoh $H$, Nishino $T$, Tomita $K$, Tsutsui $H$ : Fasting triglyceride is a significant risk factor for coronary artery disease in middle-aged Japanese men: Results from a 10-year cohort study. Circ J 2006, 70:227-31.

4. Jeppesen J, Hein HO, Suadicani P, Gyntelberg F: Triglyceride concentration and ischemic heart disease: an eight-year follow-up in the Copenhagen Male Study. Circulation 1998, 97:1029-36.

5. Achari $V$, Thakur AK: Association of major modifiable risk factors among patients with coronary artery disease-a retrospective analysis. J Assoc Physicians India 2004, 52:103-8.

6. März W, Scharnagl H, Winkler K, Tiran A, Nauck M, Boehm BO, Winkelmann BR: Low-density lipoprotein triglycerides associated with low-grade systemic inflammation, adhesion molecules, and angiographic coronary artery disease: the Ludwigshafen Risk and Cardiovascular Health study. Circulation 2004, 110:3068-74.

7. Kwiterovich PO Jr, Coresh J, Smith HH, Bachorik PS, Derby CA, Pearson TA: Comparison of the plasma levels of apolipoproteins $B$ and $A-1$, and other risk factors in men and women with premature coronary artery disease. Am J Cardiol 1992, 69:1015-21.

8. Durrington PN, Hunt L, Ishola M, Kane J, Stephens WP: Serum apolipoproteins $\mathrm{Al}$ and $\mathrm{B}$ and lipoproteins in middle aged men with and without previous myocardial infarction. Br Heart J 1986, 56:206-12.

9. Boden WE: High-density lipoprotein cholesterol as an independent risk factor in cardiovascular disease: Assessing the data from Framingham to the Veterans Affairs High-Density Lipoprotein Intervention Trail. Am J Cardiol 2000, 86:19L-22L.

10. Gordon DJ, Rifkind BM: High-density lipoprotein - the clinical implications of recent studies. N Engl J Med 1989, 321:1311-6.
11. Ruixing $Y$, Yuming $C$, Shangling $P$, Fengping $H$, Tangwei $L$, Dezhai $Y$ Jinzhen $W$, Limei $Y$, Weixiong $L$, Rongshan $L$, Jiandong $H$ : Effects of demographic, dietary and other lifestyle factors on the prevalence of hyperlipidemia in Guangxi Hei Yi Zhuang and Han populations. Eur J Cardiovasc Prev Rehabil 2006, 13:977-84.

12. Ellison RC, Zhang Y, Qureshi MM, Knox S, Arnett DK, Province MA, Investigators of the NHLBI Family Heart Study: Lifestyle determinants of high-density lipoprotein cholesterol: the National Heart, Lung, and Blood Institute Family Heart Study. Am Heart J 2004, 147:529-35.

13. Criqui MH, Cowan LD, Tyroler HA, Bangdiwala S, Heiss G, Wallace RB, Cohn R: Lipoproteins as mediators for the effects of alcohol consumption and cigarette smoking on cardiovascular mortality: results form the Lipid Research Clinics Follow-up Study. Am J Epidemiol 1987, 126:629-37.

14. Craig WY, Palomaki GE, Haddow JE: Cigarette smoking and serum lipid and lipoprotein concentrations: An analysis of published data. BMJ 1989, 298:784-8

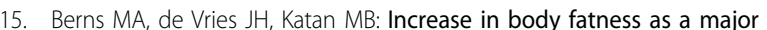
determinant of changes in serum total cholesterol and high density lipoprotein cholesterol in young men over a 10-year period. Am J Epidemiol 1989, 130:1109-22.

16. Durstine $\mathrm{J}$, Grandjean PW, Davis PG, Ferguson MA, Alderson NL, DuBose KD: Blood lipid and lipoprotein adaptations to exercise: A quantitative analysis. Sports Med 2001, 31:1033-62.

17. Ruixing $Y$, Jinzhen W, Weixiong L, Yuming C, Dezhai $Y$, Shangling P: The environmental and genetic evidence for the association of hyperlipidemia and hypertension. J Hypertens 2009, 27:251-8.

18. Heller DA, de Faire U, Pedersen NL, Dahlén G, McClearn GE: Genetic and environmental influences on serum lipid levels in twins. $N$ Engl J Med 1993, 328:1150-6.

19. Steinmetz J, Boerwinkle E, Gueguen R, Visvikis S, Henny J, Siest G: Multivariate genetic analysis of high density lipoprotein particles. Atherosclerosis 1992, 92:219-27.

20. Cuchel M, Rader DJ: Genetics of increased HDL cholesterol levels. Insights into the relationship between $\mathrm{HDL}$ metabolism and atherosclerosis. Arterioscler Thromb Vasc Biol 2004, 23:1710-2.

21. Jaye M, Lynch K, Krawiec J, Marchadier D, Maugeais C, Doan K, South V, Amin D, Perrone M, Rader D: A novel endothelial-derived lipase that modulates HDL metabolism. Nat Genet 1999, 21:424-8.

22. Hirata K, Dichek HL, Cioffi JA, Choi SY, Leeper NJ, Quintana L, Kronmal GS, Cooper AD, Quertermous T: Cloning of a unique lipase from endothelial cells extends the lipase gene family. J Biol Chem 1999, 274:14170-5.

23. Rader DJ, Jaye M: Endothelial lipase: a new member of the triglyceride lipase gene family. Curr Opin Lipidol 2000, 11:141-7.

24. McCoy MG, Sun GS, Marchadier D, Maugeais C, Glick JM, Rader DJ: Characterization of the lipolytic activity of endothelial lipase. J Lipid Res 2002, 43:921-9.

25. Choi SY, Hirata K, Ishida T, Quertermous T, Cooper AD: Endothelial lipase: a new lipase on the block. J Lipid Res 2002, 43:1763-9.

26. Ishida T, Choi S, Kundu RK, Hirata K, Rubin EM, Cooper AD, Quer-termous T: Endothelial lipase is a major determinant of HDL level. J Clin Invest 2003, 111:347-55.

27. Ma K, Cilingiroglu M, Otvos JD, Ballantyne CM, Marian AJ, Chan L: Endothelial lipase is a major genetic determinant for high-density lipoprotein concentration, structure, and metabolism. Proc Natl Acad SCi USA 2003, 100:2748-53.

28. Jin W, Millar JS, Broedl U, Glick JM, Rader DJ: Inhibition of endothelial lipase causes increased HDL cholesterol levels in vivo. J Clin Invest 2003, 111:357-62

29. Mank-Seymour AR, Durham KL, Thompson JF, Seymour AB, Milos PM: Association between single-nucleotide polymorphisms in the endothelial lipase (LIPG) gene and high-density lipoprotein cholesterol levels. Biochim Biophys Acta 2004, 1636:40-6.

30. Hutter CM, Austin MA, Farin FM, Viernes HM, Edwards KL, Leonetti DL, McNeely MJ, Fujimoto WY: Association of endothelial lipase gene (LIPG) haplotypes with high-density lipoprotein cholesterol subfractions and apolipoprotein Al plasma levels in Japanese Americans. Atherosclerosis 2006, 185:78-86.

31. Badellino KO, Wolfe ML, Reilly MP, Rader DJ: Endothelial lipase concentrations are increased in metabolic syndrome and associated with coronary atherosclerosis. PLoS Med 2006, 3:e22. 
32. Halverstadt A, Phares DA, Ferrell RE, Wilund KR, Goldberg AP, Hagberg JM: High-density lipoprotein-cholesterol, its subfractions, and responses to exercise training are dependent on endothelial lipase genotype. Metabolism 2003, 52:1505-11.

33. Yamakawa-Kobayashi K, Yanagi H, Endo K, Arinami T, Hamaguchi H: Relationship between serum HDL-C levels and common genetic variants of the endothelial lipase gene in Japanese school-aged children. Hum Genet 2003, 113:311-5.

34. deLemos AS, Wolfe ML, Long CJ, Sivapackianathan R, Rader DJ: Identification of genetic variants in endothelial lipase in persons with elevated high-density lipoprotein cholesterol. Circulation 2002, 106:1321-6.

35. Smith CE, Arnett DK, Tsai MY, Lai CQ, Parnell LD, Shen J, Laclaustra M, Junyent M, Ordovás JM: Physical inactivity interacts with an endothelial lipase polymorphism to modulate high density lipoprotein cholesterol in the GOLDN study. Atherosclerosis 2009, 206:500-4

36. Edmondson AC, Brown RJ, Kathiresan S, Cupples LA, Demissie $S$, Manning AK, Jensen MK, Rimm EB, Wang J, Rodrigues A, Bamba V, Khetarpal SA, Wolfe ML, Derohannessian S, Li M, Reilly MP, Aberle J, Evans D, Hegele RA, Rader DJ: Loss-of-function variants in endothelial lipase are a cause of elevated HDL cholesterol in humans. J Clin Invest 2009, 119:1042-50

37. Shimizu M, Kanazawa K, Hirata K, Ishida T, Hiraoka E, Matsuda Y, Iwai C, Miyamoto Y, Hashimoto M, Kajiya T, Akita H, Yokoyama M: Endothelial lipase gene polymorphism is associated with acute myocardial infarction, independently of high-density lipoprotein-cholesterol levels. Circ J 2007, 71:842-6.

38. Ruixing Y, Qiming F, Dezhai Y, Shuquan L, Weixiong L, Shangling P, Hai W, Yongzhong $Y$, Feng $H$, Shuming $Q$ : Comparison of demography, diet, lifestyle, and serum lipid levels between the Guangxi Bai Ku Yao and Han populations. J Lipid Res 2007, 48:2673-81.

39. Ruixing Y, Dezhai Y, Shuquan L, Yuming C, Hanjun Y, Qiming F, Shangling $P$, Weixiong $L$, Jing T, Yiyang L: Hyperlipidaemia and its risk factors in the Guangxi Bai Ku Yao and Han populations. Public Health Nutr 2009, 12:816-24.

40. People's Republic of China-United States Cardiovascular and Cardiopulmonary Epidemiology Research Group: An epidemiological study of cardiovascular and cardiopulmonary disease risk factors in four populations in the People's Republic of China. Baseline report from the P.R.C.-U.S.A. Collaborative Study. Circulation 1992, 85:1083-96.

41. Wu J, Yin R, Lin W, Pan S, Yang D: Hepatic lipase gene $-514 C / T$ polymorphism in the Guangxi Hei Yi Zhuang and Han populations. Lipids 2008, 43:733-40.

42. Yijiang $Z$, Ruixing $Y$, Yiyang $L$, Yaju D, Shangling $P$, Weixiong $L$, Dezhai $Y$ : Association of TaqIB polymorphism in the cholesteryl ester transfer protein gene with serum lipid levels in the Guangxi Hei Yi Zhuang and Han populations. J Investig Med 2008, 56:847-57.

43. Ruixing $Y$, Weixiong $L$, Hanjun $Y$, Dezhai $Y$, Shuquan $L$, Shangling $P$, Qiming F, Jinzhen W, Jianting G, Yaju D: Diet, lifestyle, and blood pressure of the middle-aged and elderly in the Guangxi Bai Ku Yao and Han populations. Am J Hypertens 2008, 21:382-7

44. Ruixing $Y$, Shangling $P$, Shuquan L, Dezhai $Y$, Weixiong L, Qiming F, Yuming C, Yaoheng H, Yijiang Z, Qinchen L: Comparison of hypertension and its risk factors between the Guangxi Bai Ku Yao and Han populations. Blood Press 2008, 17:306-16.

45. Cooperative Meta-analysis Group of China Obesity Task Force: Predictive values of body mass index and waist circumference to risk factors of related diseases in Chinese adult population. Chin J Epidemiol 2002, 23:5-10.

46. Paradis ME, Couture P, Bosse $Y$, Despres JP, Perusse L, Bouchard C, Vohl MC, Lamarche B: The T1111 mutation in the EL gene modulates the impact of dietary fat on the HDL profile in women. J Lipid Res 2003, 44:1902-8.

47. Tang NP, Wang LS, Yang L, Zhou B, Gu HJ, Sun QM, Cong RH, Zhu HJ, Wang B: Protective effect of an endothelial lipase gene variant on coronary artery disease in a Chinese population. J Lipid Res 2008, 49:369-75.

48. Jaye $\mathrm{M}$, Krawiec J: Endothelial lipase and HDL metabolism. Curr Opin Lipidol 2004, 15:183-9.

49. Park HS, Yun YS, Park JY, Kim YS, Choi JM: Obesity, abdominal obesity, and clustering of cardiovascular risk factors in South Korea. Asia Pac J Clin Nutr 2003, 12:411-8.
50. Jenkins DJ, Kendall CW, Axelsen M, Augustin LS, Vusksan V: Viscous and nonviscous fibres, nonabsorbable and low glycaemic index carbohydrates, blood lipids and coronary heart disease. Curr Opin Lipidol 2000, 11:49-56.

51. Anderson JW, Johnstone BM, Cook-Newell ME: Meta-analysis of the effects of soy protein intake on serum lipids. N Engl J Med 1995, 333:276-82.

52. Tomotake H, Yamamoto N, Yanaka N, Ohinata H, Yamazaki R, Kayashita J, Kato N: High protein buckwheat flour suppresses hypercholesterolemia in rats and gallstone formation in mice by hypercholesterolemic diet and body fat in rats because of its low protein digestibility. Nutrition 2006, 22:166-73

53. Ludvik BH, Mahdjoobian K, Waldhaeusl W, Hofer A, Prager R, KautzkyWiller A, Pacini G: The effect of Ipomoea batatas (Caiapo) on glucose metabolism and serum cholesterol in patients with type 2 diabetes: a randomized study. Diabetes Care 2002, 25:239-40.

54. Adaramoye OA, Achem J, Akintayo OO, Fafunso MA: Hypolipidemic effect of Telfairia occidentalis (fluted pumpkin) in rats fed a cholesterol-rich diet. J Med Food 2007, 10:330-6.

55. Ren HY, Sun HG, Ma JZ, Zhang Y, Yi CR, Wu MX, Liu WL, Li GL: Experimental study on the effects of hemp fruit oil on serun lipid levels and lipid peroxidation. Chin J Tradit Med Sci Technol 1997, 4:200.

56. Ren HY, Sun HG, Zhang Y, Yi CR, Wu MX, Li GL, Liu WL: Lipid-lowering and antiatherosclerotic effects of hemp fruit oil in partridges. Henan Tradit Chin Med 1998, 18:294-5.

doi:10.1186/1476-511X-9-110

Cite this article as: Liu et al:: Association of the LIPG 584C > T polymorphism and serum lipid levels in the Guangxi Bai Ku Yao and Han populations. Lipids in Health and Disease 2010 9:110.

\section{Submit your next manuscript to BioMed Central and take full advantage of:}

- Convenient online submission

- Thorough peer review

- No space constraints or color figure charges

- Immediate publication on acceptance

- Inclusion in PubMed, CAS, Scopus and Google Scholar

- Research which is freely available for redistribution

Submit your manuscript at www biomedcentral com/submit
C Biomed Central 